\title{
Word length, phonemic, and visual similarity effects in poor and normal readers
}

\author{
ALAN M. McNEIL \\ University of St. Andrews, St. Andrews, Scotland \\ and \\ RHONA S. JOHNSTON \\ University of Hull, Hull, England
}

\begin{abstract}
Serial order recall for visually and auditorily presented stimuli was examined in a group of 12-year-old poor readers and 7-year-old reading-age controls. With pictorial presentation, the poor readers showed a visual similarity effect, no word length effect, and a smaller phonemic similarity effect than that of controls. However, with visual presentation of printed words and with auditory presentation, poor readers showed word length and phonemic similarity effects of similar magnitude to that of controls. It is concluded that poor readers rely on visual information in tasks where the presented images are highly codable, and where verbal recoding is not obligatory, but that they will make use of phonological coding when the stimuli are not as easily codable visually in memory.
\end{abstract}

It is widely held that phonological processing deficits underlie the difficulties faced by many poor readers (Bradley \& Bryant, 1978; Bruck \& Treiman, 1990; Jorm \& Share, 1983). The literature abounds with findings that poor readers' deficiencies are in some way connected to inefficiency in using phonological information in both memory and reading-related tasks. Much of the empirical evidence points to deficits in verbal short-term memory (Brady, Shankweiler, \& Mann, 1983; Jorm, 1983). However, although memory impairments have been found in poor readers' recall of digits, letters, words, and sentences, they have not been found in poor readers' recall of unnamed abstract shapes (Swanson, 1984) or letters from an unfamiliar orthography (Vellutino, Pruzek, Steger, \& Meshoulam, 1973). These memory deficits therefore appear to be specific to verbal, but not visual, short-term memory processes (Swanson, 1984; Vellutino, 1979; Vellutino \& Scanlon, 1987). Thus, what is known about dyslexia and its relationship to speech and language difficulties appears to be consistent with a phonological (verbal coding) deficit hypothesis; poor readers encounter difficulty when visual stimuli have to be named (Swanson, 1987; Vellutino, 1977, 1979).

The issue arises as to whether poor readers' memory problems are a result of reduced memory capacity for ver-

A.M.M. is now at the University of York. The work was conducted while A.M.M. was a PhD student at the University of St. Andrews. We thank the Primary 3 pupils and staff at Glebelands Primary School in Dundee. A special mention is also due the pupils and their teachers at Clermiston and Craiglockhart reading units in Edinburgh for their support and assistance with this and other projects over the years. Correspondence should be addressed to R. S. Johnston, Department of Psychology, University of Hull, Hull HU6 7RX, England (e-mail: r.s.johnston@ hull.ac.uk). bal information, or whether these difficulties are more managerial in nature. With respect to the latter, it is known that poor readers are less adept in their application and/or maintenance of phonological information in short- and long-term memory tasks (Hulme \& Mackenzie, 1992; Vellutino, 1979). However, it is also known that poor readers' memory spans are significantly shorter than those of their chronological-age counterparts (Holligan \& Johnston, 1988; Johnston, Rugg, \& Scott, 1987; Jorm, 1983; Rugel, 1974; Torgesen, 1978). Thus, the poor reader's reduced memory performance could stem from difficulties encountered in applying, maintaining, or retrieving phonological information in serial order recall tasks, producing the widely reported memory difficulties noted for chronological age.

The present study examined poor readers' memory problems within the framework of the working memory model. This model proposes a dual role for the phonological loop: conversion of visual inputs into auditory form and maintenance of that information. The phonological similarity effect shows whether the phonological store is being used, and the word length effect examines the use of rehearsal. The phonemic similarity effect has been found in adults and older children. It is attributed to a passive phonological store contained within the phonological loop component of working memory (Baddeley, 1986). The poorer recall of similar sounding items over dissimilar items is said to be due to the nature of the passive phonological store; because information is stored phonologically, similar sounding items become confused as the distinctive phonological information decays. The other effect attributed to the functioning of the phonological loop is that of word length, which refers to the finding that memory span for words of short-spoken duration is greater than for words of longer 
duration. This effect has also been found in adults (Baddeley, Thomson, \& Buchanan, 1975) and in children from 5 upward with auditory presentation (Hitch, Halliday, \& Littler, 1993), and 8 upward with pictorial presentation (Hitch, Halliday, Dodd, \& Littler, 1989; Hitch, Halliday, Schaafstal, \& Schraagen, 1988). A linear relationship has been found between the number of items that can be recalled and the rate at which these can be articulated (Baddeley et al., 1975; Nicholson, 1981); faster rates of articulation would result in more items being rehearsed and recalled. Items of long spoken duration take longer to articulate and therefore receive less rehearsal in the phonological loop, and are more likely to be forgotten. Phonemic similarity and word length effects are found with both visual and auditory presentation; auditorily presented materials gain direct access to the phonological store, whereas visually presented items must be phonologically recoded in order to gain entry as a verbal form (Baddeley, 1986). With visual presentation in adult subjects, when articulation is suppressed the effects of word length and phonemic similarity are abolished, thus supporting the attribution of these effects to phonological rehearsal processes (Baddeley, 1986; Baddeley et al., 1975; Murray, 1968).

It is now well established that there is a developmental progression in the way in which children store a series of familiar pictured objects for immediate recall. In middle childhood, children start to show evidence of using phonological coding, as shown by the emergence of phonemic similarity (e.g., Conrad, 1971; Hitch, Woodin, \& Baker, 1989) and word length effects (Hitch et al., 1988; Hitch, Halliday, et al., 1989). With pictorial presentation, phonological similarity and word length effects are rarely reported in children under the age of 7, but are fully reliable by the age of 11 (Hitch \& Halliday, 1983; Hulme, Thomson, Muir, \& Lawrence, 1984), whereas with spoken material these effects are detectable in children as young as 4 or 5 (Gathercole \& Hitch, 1993; Henry, 1991; Hulme, 1987; Hulme et al., 1984). There is thus evidence that it is not until around the ages of 7 to 8 that children start to use both the passive phonological store and the rehearsal component of the phonological loop for stimuli that have to be actively converted into phonological form. It may be no coincidence that this usage develops around the same age that children start to verbally rehearse (Kail, 1984). Investigations have been carried out to examine the type of coding that is used by children who are too young to be able to verbally rehearse. Using a fixed length blocked trial procedure, Hitch et al. (1988) presented 5- and 10-year-old children with one-syllable visually similar and one- and three-syllable visually dissimilar items for recall. It was predicted that the use of visual memory codes by 5 -yearolds would cause disruption of recall for visually similar stimuli, in the absence of a word length effect. Conversely, 10 -year-olds were expected to show effects of word length, but not of visual similarity. The results confirmed these predictions overall, although the 5-year-olds also showed a word length effect, suggesting that both forms of coding were available to them.
It has been proposed that poor readers are immature in the development of the use of phonological coding in working memory. Such a conclusion would be reinforced by evidence that they used visual coding instead (i.e., the demonstration of visual similarity effects). Although it has been found that poor readers fail to show phonemic similarity effects with letters and words (Mann, Liberman, \& Shankweiler, 1980; Shankweiler, Liberman, Mark, Fowler, \& Fischer, 1979), several studies have failed to replicate these findings (Hall, Wilson, Humphreys, Tinzmann, \& Bowyer, 1983; Johnston, 1982; Johnston, Rugg, \& Scott, 1987). Given that poor readers' memory spans are markedly reduced with chronological age (Holligan \& Johnston, 1988; Johnston, Rugg, \& Scott, 1987; Jorm, 1983; Rugel, 1974; Torgesen, 1978), it has been argued that the lack of phonological similarity effects in many investigations can be explained by poor readers being given as many items to recall as their chronological-age controls. Holligan and Johnston found that 8-year-old poor readers and their readingage (RA) controls showed normal phonological similarity effects with visual presentation of letters when the task was set at an appropriate level of difficulty, but no effects were found in either group when the number of presented items exceeded their memory spans. Evidence thus suggests that poor readers can make use of the passive phonological store, although, given their impaired memory spans for chronological age, its capacity may be reduced. None of these studies, however, investigated whether poor readers showed phonological similarity effects with pictorial presentation, so immature development might be detected in such tasks. Poor readers' impaired memory spans may be due to difficulties in using verbal rehearsal, which might be reflected in small or nonexistent word length effects. However, poor readers show normal word length effects with auditory presentation (Avons \& Hanna, 1995; Johnston \& Anderson, 1998; McDougall, Hulme, Ellis, \& Monk, 1994). With respect to pictorial presentation, Johnston and Anderson found that 11-year-old poor readers failed to show word length effects, which suggests a reliance on visual memory codes in situations where the use of a phonological code is not obligatory.

Under most circumstances, poor readers seem to exhibit normal effects of both phonological similarity and word length, but with highly codable pictorial stimuli it would appear that they show atypical patterns of performance. There are no studies of word length effects with printed word presentation in poor readers, and no studies of phonological similarity effects with pictorial presentation. Although the majority of words are visually distinct for the purposes of word recognition, they would not be easy to retain as distinct visual representations in shortterm memory, so poor readers might be more likely to use phonological coding with print than with pictures.

In the present study, four experiments investigated poor readers' and RA controls' immediate memory for visually and auditorily presented materials. Although Johnston and Anderson (1998) demonstrated that poor readers did not show word length effects with pictorial presentation, 
Table 1

Participant Characteristics

\begin{tabular}{ccrrr}
\hline Participants & $n$ & CA & RA & \multicolumn{1}{c}{ IQ } \\
\hline Poor & & & & \\
$M$ & 18 & 12.01 & 8.12 & 109.25 \\
$S D$ & & 0.73 & 1.04 & 11.94 \\
Controls & & & & \\
$M$ & 19 & 7.58 & 8.14 & 106.17 \\
$S D$ & & 0.33 & 0.51 & 9.30 \\
\hline
\end{tabular}

Note $-\mathrm{CA}=$ chronological age, $\mathrm{RA}=$ reading age .

they did not investigate whether poor readers had visual coding available to them as an alternative form of coding. The present study therefore examined whether visual similarity between pictures was disruptive of recall in poor readers. Further experiments examined whether poor readers would show word length and phonemic similarity effects with pictorial, printed word, and auditory presentation. It was predicted that with pictorial presentation (Experiment 1), poor readers would not show either a word length effect (in replication of Johnston and Anderson's findings) or a phonemic similarity effect because of a reliance on visual coding. However, it was hypothesized that poor readers would show normal word length and phonemic similarity effects with printed word (Experiment 3 ) and auditory presentation (Experiments 2 and 4) because these stimuli are not as easily codable into visual form.

\section{EXPERIMENT 1}

\section{Method}

Participants. Thirty-seven children were studied. Eighteen of these were poor readers identified as having specific reading disabilities. Ten of the poor reader participants were attending a reading unit for intensive remedial tuition twice weekly for half-day periods. The remaining poor readers had completed this 2-year program and were attending their 1 st year of secondary school. Children were selected to attend the unit on the basis of IQs above 90 . Participation in the study required that each of these children had a reading age that was a minimum of 2 years behind his/her chronological age. The mean chronological age of the poor readers was 12.01 years $(S D=.729)$. The 19 normal $(\mathrm{RA})$ controls attended a single school with an extensive catchment area and were drawn from two separate Primary 3 classes. Their mean chronological age was 7.58 years $(S D=.328)$. The two groups were matched on the British Abilities Scales Test of Word Reading (Elliott, Murray, \& Pearson, 1977), and the Wechsler Intelligence Scale for Children-Revised (WISC-R; Wechsler, 1974) four-test short form (Maxwell, 1959), as prorated by the method adopted by Sattler (1982). All of the experiments described in the following studies were carried out with the same participants, individually tested in separate sessions. The group characteristics are presented in Table 1.

Materials. The stimuli that were used for each of the four conditions in Experiment 1 comprised eight common nouns that were matched for word frequency (Carroll, Davies, \& Richman, 1971), and where possible for age of acquisition (Carroll \& White, 1973). The four lists were as follows: phonemically similar items (cat, cap, mat, bat, map, tap, hat, rat); visually similar items (bat, comb, spade, saw, fork, pen, key, nail); one-syllable items (king, leaf, tent, rope, tree, snake, knife, horse); three-syllable items (strawberry, umbrella, envelope, banana, ambulance, butterfly, policeman, elephant). One- syllable items served as the control set against which the effects of word length, phonemic similarity, and visual similarity could be gauged. The visually similar items were elongated objects, which all shared the same angle of orientation. The shared elongated appearance and angle of orientation of this set of items has in previous investigations (see Hayes \& Schulze, 1977; Hitch et al., 1988) been judged to account for the objects being visually similar in spite of the obvious individual physical differences (e.g., pen and fork). List length was set at four items. This was established on the basis of these children's mean recall performance on the WISC-R Digit Span subtest. Similarly, it has been noted that floor effects have been present in investigations (albeit under the conditions of articulatory suppression) using older participants (aged 24-70), where span length was set at five items (Baddeley, Lewis, \& Vallar, 1984). Hitch et al. (1989) chose sequence lengths of five and three for normally developing 11- and 5-year-old children, respectively.

Procedure. Pictures for each of the four conditions were individually presented on the computer screen to be named by the child immediately prior to the test trials for each condition. This was done to ensure correct naming of items. Any failure to produce the required name was corrected. For the memory task, the pictures were presented one at a time on a computer screen, at the rate of one item per second, with 1-sec intervals between each. In order to cue recall, an asterisk appeared in the center of the screen after the presentation of the four pictures, after which the participant was required to report what had been presented. Thus, the child was told, "I am going to show you some pictures on the computer. When all of the pictures have been shown you will see a star sign in the center of the screen, and that is when I want you to tell me what the pictures were. Try to remember these in order." Participants were presented with eight trials for each type of material, with sequence length set at four items. Two practice trials comprising a mixture of stimuli from the four conditions were presented in order to demonstrate to the children what would be expected of them in the test trials. The presentation of the test trials commenced if one of these was correctly recalled in serial order. (None of the children required additional practice trials; i.e., all children correctly reported at least one of the two practice trials prior to testing.) Memory span performance was recorded as the total number of trials correctly reported in serial order. Trials were blocked by condition (i.e., by type of material), and the order of blocks was counterbalanced across participants.

It should be noted that Experiment 2 (auditory memory) was carried out around 3 weeks after this experiment, with a minimum gap of 2 weeks. This order of presentation was adopted because prior presentation of an auditory condition might have evoked a verbal coding strategy in the poor readers in the pictorial presentation experiment, which would have obscured their normal method of dealing with such stimuli.

\section{Results}

The total number of four-picture sequences recalled in correct serial order for the test trials was calculated for each condition and converted to a percentage form. These data

Table 2

Experiment 1: Mean Percentage Correct for Visually Presented Phonemically Similar (PS), Visually Similar (VS), One-Syllable, and Three-Syllable Pictorial Stimuli Conditions

\begin{tabular}{ccccc}
\hline Participants & PS & VS & One & Three \\
\hline Poor & & & & \\
$M$ & 42.36 & 44.44 & 60.42 & 53.47 \\
$S D$ & 21.50 & 25.08 & 16.18 & 20.92 \\
Controls & & & & \\
$M$ & 23.03 & 46.71 & 59.21 & 30.92 \\
$S D$ & 22.15 & 22.76 & 30.86 & 29.07 \\
\hline
\end{tabular}


were analyzed by a two-way repeated measures analysis of variance (ANOVA). There was one between-subjects factor, groups (poor vs. RA controls), and one within-subjects factor, condition (phonemically similar, visually similar, and one- and three-syllable items). The means and standard deviations are presented in Table 2.

The main effect of groups was not significant $[F(1,35)=$ $2.94, p>.05]$. However, the analysis showed a main effect of condition $[F(3,105)=16.19, p<.001]$ and an interaction between groups and condition $[F(3,105)=5.04$, $p<.01]$. Newman-Keuls post hoc analysis of the groups $\times$ condition interaction showed that (in terms of phonemic similarity effects) the normal readers' performance for one-syllable items was significantly better than their performance for phonemically similar items $(p<.01)$. This was also true for the poor reader group $(p<.05)$. However, since the RA controls showed a phonemic similarity effect twice the size of that of the poor readers, a Scheffé test comparing differences between pairs of means was carried out. It was found that the poor readers showed a significantly smaller phonological similarity effect than did the RA controls.

As far as effects of word length were concerned, the normal readers recalled one-syllable stimuli better than threesyllable items $(p<.01)$, but no such difference emerged for poor readers. However, the poor readers' recall of onesyllable stimuli was better than that of visually similar items $(p<.05)$, thus demonstrating an effect of visual similarity; no such effect was found for RA controls. However, a Scheffé test comparing pairs of means showed that the size of the visual similarity effect did not differ between the two groups. Thus, although only the poor readers showed a reliable visual similarity effect, the magnitude of the poor readers' effect could not be distinguished from that of RA controls. Finally, poor readers remembered phonemically similar items and three-syllable items better than the RA controls did $(p<.01)$.

\section{Discussion}

Post hoc analysis of the groups $\times$ condition interaction revealed that normal readers showed effects of both phonemic similarity and word length. The poor readers showed no word length effect and had a phonemic similarity effect of smaller magnitude than that of RA controls. On the other hand, the poor readers demonstrated a visual similarity effect, whereas this was not quite significant for the normal readers. Hitch et al. (1988) did not find evidence of visual coding in normal 11-year-olds, and thus the pattern of results for the poor readers in the present investigation indicates immaturity for their chronological age. In fact, they show an effect, which is no longer reliable even in the 7.6-year-old RA controls. These results suggest that poor readers rely more on visual codes than on verbal labels to assist recall of pictorial stimuli. However, the poor readers, as well as the RA controls, were observed to make lip movements during the task and sometimes reported that they said the names of the pictures in order to remember them.

\section{EXPERIMENT 2}

It was predicted in Experiment 2 that with auditory presentation poor readers would show phonemic similarity and word length effects like those of their RA controls. It was further predicted that neither group would show a visual similarity effect given that these "visually similar" one-syllable items from Experiment 1 were matched to the one-syllable control set and that in this instance presentation was auditory and not visual.

\section{Method}

Materials. The items used in Experiment 2 were identical to those used in Experiment 1, but presentation was auditory.

Procedure. Experiment 2 followed the same procedure as Experiment 1 , except that presentation was auditory. Items from each of the four conditions were read to each participant prior to the test trials in order to familiarize participants with the items that would be heard in the test trials. The additional purpose of presenting these prior to the commencement of each condition was to reduce the possibility of carryover of pictorial representations of the stimuli from the previous experiment. Timing was paced by the experimenter's use of a visual metronome as the names of the pictures used in Experiment 1 were read. Upon the completion of presentation of the four items, the experimenter's saying of the word now cued the request for recall.

\section{Results}

The total number of four-word sequences recalled in correct serial order was calculated for each condition and converted to percentage form. These data were analyzed by a two-way repeated measures ANOVA. There was one between-subjects factor, groups (poor vs. RA controls), and one within-subjects factor, condition (phonemically similar, visually similar, and one- and three-syllable items). The means and standard deviations are presented in Table 3.

The main effect of groups was not significant $[F(1,35)=$ $.01, p>.05]$. However, the analysis showed a main effect of condition $[F(1,35)=134.34, p<.01]$ and an interaction between groups and condition $[F(3,105)=3.94, p<$ $.05]$. Newman-Keuls tests on the groups $\times$ condition interaction showed that RA controls recalled one-syllable items better than either phonemically similar items $(p<$ $.01)$ or three-syllable items $(p<.01)$. For the poor readers, one-syllable items were similarly recalled better than phonemically similar items $(p<.01)$ and three-syllable items $(p<.01)$. However, a Scheffé test comparing pairs of means showed that RA controls had a significantly

Table 3

Experiment 2: Mean Percentage Correct for Auditorily Presented Phonemically Similar (PS), Visually Similar (VS), One-Syllable, and Three-Syllable Stimuli

\begin{tabular}{ccccc}
\hline Participants & PS & VS & One & Three \\
\hline Poor & & & & \\
$M$ & 15.28 & 67.37 & 79.86 & 41.67 \\
$S D$ & 12.54 & 17.75 & 17.75 & 23.48 \\
Controls & & & & \\
$M$ & 22.37 & 75.66 & 71.05 & 33.55 \\
$S D$ & 16.45 & 24.46 & 19.12 & 20.43 \\
\hline
\end{tabular}


smaller phonemic similarity effect than did the poor readers. The poor readers recalled significantly more one-syllable items than visually similar items $(p<.05)$, even though presentation was auditory and the two sets of items were matched for word length.

\section{Discussion}

Although the poor readers failed to show a word length effect with the presentation of pictorial stimuli in Experiment 1 , they showed normal word length effects with auditory presentation in Experiment 2. In Experiment 1, the poor readers showed significantly smaller phonemic similarity effects with pictorial presentation than controls, but with auditory presentation in Experiment 2 the effect was of greater magnitude. It would therefore appear that with pictorial presentation, poor readers might opt out of using a verbal code for remembering serially presented stimuli, although they are capable of using such codes with auditory presentation. However, closer inspection of the phonemic similarity effect showed that the magnitude of this effect was greater in the poor readers. This difference is a result of the poor readers' slightly poorer recall of phonemically similar items alongside a slight enhancement of recall for one-syllable items. It has been shown that the size of this effect increases with age - phonemic similarity has progressively more effect on recall with increasing age (Hulme, 1984; Hulme \& Tordoff, 1989). Thus, in an RA match design, one might expect older poor readers to show a greater effect. Nevertheless, although it may indicate a qualitative change in the sensitivity of the phonological store with age, it is a finding that is worthy of some further investigation.

These issues aside, the phonemic similarity and word length effects found in poor readers with auditory presentation suggest that when they are forced to make use of phonological information, they demonstrate normal processing. However, the fact that they showed a visual similarity effect in the auditory experiment suggests that poor readers may also attempt to "picture" spoken items as a means of remembering the presented information. Indeed there were four spontaneous self-reports by the dyslexics that they were trying to "see" what had been said. Given that the pictorial experiment preceded the auditory experiment, the children may have been making use of mental images generated from their memory of the stimuli presented 2 weeks earlier.

\section{EXPERIMENT 3}

The order of presentation of Experiments 3 and 4 was counterbalanced across participants and occurred between 1 and 2 weeks after Experiments 1 and 2.

Although it is theoretically possible that with visual presentation of printed words poor readers might make use of visual memory coding, it was predicted that the poor readers would be forced to rely on a phonological code given that printed words are not as easily maintained in a visual store as pictures (Swanson, 1984). Therefore, under these conditions the poor readers were expected to demonstrate normal effects of both phonemic similarity and word length.

\section{Method}

Materials. The stimuli used in Experiment 3 were identical to those used in Experiments 1 and 2 with the exception of the visually similar stimulus set, which was replaced by a two-syllable stimulus condition (giraffe, hammer, iron, ladder, mountain, rabbit, table, window), matched to the other sets for both frequency and age of acquisition. Thus, the four respective conditions comprised phonemically similar one-syllable words, and one-, two-, and three-syllable printed words.

Procedure. The procedure for Experiment 3 was as for Experiment 1 , except printed words rather than pictures were presented.

\section{Results}

One poor reader participant's reading accuracy on the computer display was impaired and was thus excluded from all four conditions in this particular analysis. The total number of four-word sequences recalled in correct serial order was calculated for each condition and converted to percentage form. These data were analyzed by a twoway repeated measures ANOVA. There was one betweensubjects factor, groups (poor vs. RA controls), and one within-subjects factor, condition (phonemically similar and one-, two-, and three-syllable items). The means and standard deviations are presented in Table 4.

The main effect of groups was not significant $[F(1,34)=$ $.01, p>.05]$. The analysis showed a main effect of condition $[F(3,102)=69.85, p<.001]$. In terms of phonemic similarity effects, Newman-Keuls tests showed that onesyllable items were recalled better than phonemically similar items $(p<.01)$. Overall effects of word length were found, with one-syllable items being better recalled than either two-syllable $(p<.01)$ or three-syllable items $(p<$ $.01)$. Finally, two-syllable items were recalled better than three-syllable items $(p<.01)$. There was no interaction between group and condition $[F(3,102)=1.56, p>.10]$.

\section{Discussion}

There were significant effects of both word length and phonemic similarity for poor readers and RA controls when printed words were presented visually, the findings being similar to those with auditory presentation in Experiment 2. Although presentation was visual, the fact that the words were printed seemed to preclude the poor readers from being able to make use of a visual memory code,

Table 4

Experiment 3: Mean Percentage Correct for Visually Presented Phonemically Similar (PS), One-Syllable, Two-Syllable, and Three-Syllable Printed Words

\begin{tabular}{ccccc}
\hline Participants & PS & One & Two & Three \\
\hline Poor & & & & \\
$M$ & 19.85 & 72.79 & 46.32 & 29.41 \\
$S D$ & 17.71 & 19.88 & 21.09 & 14.62 \\
Controls & & & & \\
$M$ & 27.63 & 66.45 & 42.76 & 29.61 \\
$S D$ & 15.91 & 24.31 & 23.32 & 26.09 \\
\hline
\end{tabular}


print not being as highly codable as pictures in terms of establishing visual memory forms.

\section{EXPERIMENT 4}

Since printed word forms share similar visual attributes (e.g., flower-tower), there existed the possibility that in Experiment 3, recall for phonemically similar stimuli (e.g., cap, cat, map) could in part be disrupted by the shared visual properties of these words. Thus, in order to demonstrate the degree to which poor readers are truly susceptible to phonemic similarity errors, the fourth experiment used phonemically similar and phonemically dissimilar letter strings with both visual and auditory presentation. It was predicted that the poor readers would resort to verbal recoding in both the visual and auditory conditions, demonstrating normal decrements in performance for phonemically similar strings compared with RA controls.

\section{Method}

Materials. The phonemically similar letters used were $g, c, t, d$, $p, v$, and $b$, and the phonemically dissimilar letters were $r, y, l, s, z$, $h$, and $j$. There were four conditions (e.g., visually presented: phonemically similar and phonemically dissimilar, and auditorily presented: phonemically similar and phonemically dissimilar letter strings).

Procedure. The procedure for the auditory component of Experiment 4 was the same as that of Experiment 2, and for the visual component the procedure was the same as that of Experiment 1.

All items were administered in a single test session; the order of presentation of visual and verbal conditions was counterbalanced across participants, as were similar versus dissimilar items. Thus, in each group no 2 children received the same order of presentation.

\section{Results}

As in the previous experiment, 1 participant in the poor reader group was unable to complete the visual presentation condition and was thus excluded from the complete analysis involving both visual and auditory presentation. The total number of four-letter sequences recalled in correct serial order was calculated for each condition and converted to percentage form. These data were analyzed by a three-way repeated measures ANOVA. There was one between-subjects factor, groups (poor vs. RA controls), and two within-subjects factors, modality (visual and auditory presentation) and letter type (phonemically similar and phonemically dissimilar letters). The means and standard deviations are presented in Table 5.

The main effect of group was not significant $[F(1,34)=$ $1.62, p>.10]$. However, the analysis showed a main effect of modality, a result of recall being better with auditory presentation $[F(1,34)=4.86, p<.05]$. Similarly, there was a significant main effect of letter type, with phonemically dissimilar letters being better recalled than phonemically similar letters $[F(1,34)=169.71, p<.001]$. There was also an interaction between the factors of modality and letter type $[F(1,34)=5.89, p<.05]$. NewmanKeuls tests showed that phonemic similarity effects were shown with both visual and auditory presentation $(p<.01)$. However, phonemically dissimilar letter strings were bet-
Table 5

Experiment 4: Mean Percentage Correct for Visually and Auditorily Presented Phonemically Similar (PS) and Phonemically Dissimilar (PD) Letter Strings

\begin{tabular}{cccccc}
\hline & \multicolumn{2}{c}{ Visually Presented } & & \multicolumn{2}{c}{ Auditorily Presented } \\
\cline { 2 - 3 } \cline { 5 - 6 } Participants & PS & PD & & PS & PD \\
\hline Poor & & & & \\
$M$ & 35.29 & 63.24 & & 31.62 & 74.26 \\
$S D$ & 19.88 & 21.86 & & 23.43 & 17.94 \\
Controls & & & & \\
$M$ & 44.08 & 65.79 & & 46.05 & 78.95 \\
$S D$ & 27.44 & 24.24 & 24.31 & 16.17 \\
\hline
\end{tabular}

ter recalled in the auditory presentation modality $(p<.05)$, whereas there was no such difference for similar items. The group $\times$ modality, group $\times$ letter type, and group $\times$ modality $\times$ letter type interactions were not significant $\left(F_{\mathrm{S}}>.10\right)$.

\section{Discussion}

There is evidence that direct auditory input into the phonological loop enhances recall for dissimilar-sounding items. However, for similar-sounding items, the deleterious effects of entry into the phonological store are equivalent.

\section{GENERAL DISCUSSION}

The poor readers did not show a general immaturity in the development of their working memories. First, there was evidence that they made normal use of the passive phonological store when words and letters were presented both auditorily and in print form, since they showed phonemic similarity effects in these conditions. Second, since they showed word length effects with both auditory and printed word presentation, there was also evidence of normal use of the active rehearsal element of the phonological loop. What they did demonstrate was a bias toward using visual rather than verbal coding when presented with information that was easily codable in visual form. Thus they were developmentally immature compared with children having similar memory spans in that with pictorial presentation they showed no word length effect and they showed a phonemic similarity effect of reduced magnitude. The fact that they also showed a clear visual similarity effect shows that they were capable of using pictorial representations in immediate memory tasks.

It has been proposed that word length effects are in part due to processes operating during verbal output, since word length effects are smaller with probed recall (Avons, Wright, \& Pammer, 1994). However, this still leaves open the possibility that other factors, such as rehearsal, also contribute to the word length effect. Baddeley, Chincotta, Stafford, and Turk (2002) found that word length effects were still found when participants had to decide whether a second list had been presented in the same order as or in a different order from the first list. This produced a word length effect even when participants carried out articulatory suppression during presentation of the recognition 
list, suggesting a possible role for rehearsal in explaining the effect found with probed recall. Brown and Hulme (1995) have argued that word length effects can be explained in terms of redintegration processes, whereby decaying traces are supplemented by information stored in long-term memory; longer words are more prone to forgetting because they have more components. This does not rule out a rehearsal explanation of the word length effect-redintegration might affect the efficiency with which long words are rehearsed, since more components have to be retrieved for these items compared with short words, thus producing a word length effect.

The poor readers in this study used full verbal recall and yet did not show any effects of word length with pictures. There is reason to think that the poor readers encoded the words phonologically at presentation because of their lip movements and because they often reported doing so. However, they may not have attempted to carry out any cumulative verbal rehearsal. It is likely that when asked to recall the items they had seen, they visualized the pictures and then retrieved the names and verbalized them for recall. This process was apparently not a more timeconsuming one for the long words; it may be that information has to be retrieved from the phonological store, and possibly also rehearsed, in order for word length effects to be shown at output. Even 5-year-olds, who do not spontaneously rehearse and do not normally show word length effects with full verbal recall, demonstrate better recall of short as opposed to long words when trained in covert verbal rehearsal of a series of pictures (Johnston, Johnson, \& Gray, 1987). It seems likely that an instruction to rehearse for 5-year-olds encourages them to enter information into the phonological store, and that they retrieve that information from the store because they are instructed to rehearse prior to recall; the poor readers in the present investigation may have carried out only the first phase of this process (i.e., encoding without rehearsal or retrieval from the phonological store).

The poor readers did show some susceptibility to phonemic similarity in the pictorial version of the task, although the effect was smaller than would be expected for their memory spans. There are several possible explanations of this finding. A simple explanation is that the poor readers visualized the pictures at recall, and when the verbal labels for them were retrieved, there was some confusion between the similar sounding items. Although phonemic similarity effects are not thought to occur at output, support for this idea comes from a study by Henry (1991), who found that 5-year-olds did not show auditory phonemic similarity effects with probed recall, although they did with full verbal recall. However, Johnston and Conning (1990) found that 5-year-olds who were not instructed to rehearse when presented with pictures failed to show a phonemic similarity effect with full verbal recall. Given the evidence that the poor readers in the present study labeled the items at presentation, an alternative explanation is that this information entered the phonological store, where it would have become confused as the traces de- cayed. At recall, the children may then have visualized the pictures and labeled them, but in doing so decaying information from the phonological store might have been activated and so caused disruption. A full phonemic similarity effect might not be found because the pictorial information would inhibit the number of errors made in recalling the phonologically similar items. In contrast, disruptive effects would not occur in a word length task if pictures were visualized and then named at recall, and if information was also activated from the phonological store; the information retrieved from the store for the two word types would not have been differentially subjected to phonological confusion.

Although the poor readers were observed to covertly label the pictures on presentation, they also sometimes reported attempting to retain information in pictorial form, and even in some instances said that they attempted to "picture" the spoken items when presentation was auditory. It is interesting therefore that in the auditory study in Experiment 2, the poor readers also showed a "visual" similarity effect. This condition was carried out around 3 weeks after the pictorial condition, which may mean that when they visualized "bat," "comb," "spade," and so on, this evoked images at a $45^{\circ}$ orientation. Thus, the earlier presentation of a pictorial condition may have triggered the use of a visual strategy in poor readers several weeks later, but there was no evidence that it did so for the RA controls. The findings therefore indicate a strong preference by poor readers for using visual coding. Given that the capacity to use verbal coding of visual stimuli is present in poor readers in certain circumstances, it would appear that the principal difference between their memory systems and those of controls is the conditions in which visual or verbal encoding of visual stimuli is called into play. This difference in the selection of type of coding may have direct implications for understanding the nature of the poor readers' slowness to learn to recognize new words.

For normal readers, repeated exposure to visual stimuli that have verbal labels (including words) leads to the development of interconnections between the two modalities. Verbal labels are activated by the presentation of a visual stimulus, and conversely the presentation of an auditory stimulus is said to elicit its corresponding visual form (Swanson, 1987). There is evidence that poor readers lack automaticity in retrieving verbal labels, since they have slower speech onset than chronological-age controls when labeling singly presented pictures (Johnston \& Anderson, 1998), performance generally being RA appropriate. This indicates slow retrieval from long-term memory, suggesting difficulty in making connections between visual and verbal stimuli. Although performance in the Johnston and Anderson study was RA appropriate, the poor readers would have had many more exposures to these pairings in order to develop the same speed of identification. Poor readers may therefore have underspecified phonological representations for printed words in long-term memory and/or experience difficulty in accessing the information in long-term memory. Thus although poor readers are ca- 
pable of verbally labeling pictorial stimuli, it is effortful, and such difficulties may lead to immature rehearsal strategies that do not allow adequate opportunity to verbally synthesize or "chunk" information for effective storage and retrieval (Torgesen \& Goldman, 1977; Vellutino, 1977). If poor readers' verbal and visual coding systems are poorly connected (Swanson, 1987), or if they do not integrate these codes for efficient storage and/or retrieval of visual information (e.g., Vellutino, 1979), this may bias them to rely more on visual processing (Nelson \& Brooks, 1973; Swanson, 1987). In the face of inefficient phonological processing skill, poor readers may similarly be more or less forced to rely on intact visual processes to compensate for phonological impairments. Thus deficits in the phonological or verbal domain could produce a dependence on a visual approach to word recognition.

Although the poor readers in the present study showed normal use of phonological information in serial order recall tasks with printed words, this has not been shown for poor readers carrying out long-term memory tasks. Holligan and Johnston (1988) noted that when a visual recognition memory task followed a visually presented rhyme judgment task, poor readers demonstrated a bias toward the selection of orthographically similar word pairs (e.g., post-lost), whereas normal readers made proportionately more choices based on the shared phonological properties of rhyming words (rude-food). A similar bias was captured in a study in which cued recall tasks followed both visual and auditory presentation of rhyming and nonrhyming word pairs (Rack, 1985). In Rack's study, the poor readers had better recall of orthographically similar pairs than of orthographically dissimilar pairs even when the mode of presentation was auditory, which was not the case for normal readers. A similar lack of regard for phonological information has also been noted in poor readers' bias toward the categorization of words according to semantic rather than phonological properties (Bryne \& Shea, 1979; Vellutino \& Scanlon, 1987).

Poor readers seem to be prone to adopting a visual approach in memory tasks involving printed words and pictures when this form of coding is feasible. In immediate memory tasks, where lists of printed words have to be recalled in serial order, visual coding would not be a good strategy. Although words are visually distinct enough for word recognition purposes (e.g., Ehri \& Wilce, 1985; Frith, 1985; Gough \& Hillinger, 1980), this may not be adequate when trying to recall four items, as in the present study. However, in longer term memory tasks such as Holligan and Johnston's (1988), the words in the pair post-lost only differ by one letter, so a visual pairing is relatively easy to retain. Furthermore, if poor readers are prone to recognizing words on the basis of their visual characteristics, they may be better at forming visual rather than phonological connections when words are paired together. It has indeed been suggested that poor readers primarily use visual or orthographically based strategies in reading, rather than recoding visual information into a corresponding phonological form (Foorman \& Liberman, 1989; Seymour \& Porpodas, 1980; Snowling, 1980).

In conclusion, it was found that poor readers showed evidence of a preference for the visual coding of stimuli in immediate memory tasks, which was demonstrated when a pictorial form of presentation was used. This preference may occur because poor readers have difficulty in forming visual-verbal connections, so that using pictorial representations is less effortful for them than verbal coding. However, in situations where visual coding was not feasible because of the stimuli being spoken or printed words, poor readers showed normal effects of word length and phonemic similarity.

\section{REFERENCES}

Avons, S. E., \& Hanna, C. (1995). The memory-span deficit in children with specific reading disability: Is speech rate responsible? British Journal of Developmental Psychology, 13, 303-311.

Avons, S. E., Wright, K. L., \& PAMmer, K. (1994). The word-length effect in probed and serial recall. Quarterly Journal of Experimental Psychology, 47A, 207-231.

BADDELEY, A. D. (1986). Working memory. Oxford: Oxford University Press.

Baddeley, A. D., Chincotta, D., Stafford, L., \& Turk, D. (2002). Is the word length effect in STM entirely attributable to output delay? Evidence from serial recognition. Quarterly Journal of Experimental Psychology, 55A, 352-369.

Baddeley, A. D., Lewis, V. J., \& Vallar, G. (1984). Exploring the articulatory loop. Quarterly Journal of Experimental Psychology, 36. 233-252.

BaDDEley, A. D., Thomson, N., \& Buchanan, M. (1975). Word length and the structure of short-term memory. Journal of Verbal Learning \& Verbal Behavior, 14, 575-589.

BRADLEY, L., \& BRYANT, P. E. (1978). Difficulties in auditory organisation as a possible cause of reading backwardness. Nature, 271, 746-747.

Brady, S., Shankweiler, D., \& ManN, V. (1983). Speech perception and memory coding in relation to reading ability. Journal of Experimental Psychology, 35, 345-367.

Brown, G. B. A., \& Hulme, C. (1995). Modeling item length effects in memory span: No rehearsal needed? Journal of Memory \& Language, 54, 594-621.

Bruck, M., \& Treiman, R. (1990). Phonological awareness and spelling in normal children and dyslexics: The case of initial consonant clusters. Journal of Experimental Psychology, 50, 156-178.

BRyne, B., \& SheA, P. (1979). Semantic and phonetic memory codes in beginning readers. Memory \& Cognition, 7, 333-338.

Carroll, J. B., Davies, P., \& Richman, B. (1971). The word frequency book. New York: American Heritage.

Carroll, J. B., \& White, M. N. (1973). Word frequency and age of acquisition as determiners of picture-naming latency. Quarterly Journal of Experimental Psychology, 25, 85-95.

ConRaD, R. (1971). The chronology of the development of covert speech in children. Developmental Psychology, 5, 398-405.

Ehri, L. C., \& WILCE, L. S. (1985). Movement into reading: Is the first stage of printed word learning visual or phonetic? Reading Research Quarterly, 20, 163-179.

Elliott, C. D., Murray, D. J., \& Pearson, L. S. (1977). The British abilities scales Test of Word Reading. Windsor, U.K.: NFER Nelson.

Foorman, B., \& Liberman, D. (1989). Visual and phonological processing of words: A comparison of good and poor readers. Journal of Learning Disabilities, 22, 349-355.

FRITH, U. (1985). Beneath the surface of developmental dyslexia. In K. E. Patterson, J. C. Marshall, \& M. Coltheart (Eds.), Surface dyslexia: Neuropsychological and cognitive studies of phonological reading (pp. 301-330). London: Erlbaum. 
Gathercole, S. E., \& Hitch, G. J. (1993). Developmental changes in short-term memory: A revised working memory perspective. In A. F. Collins, S. E. Gathercole, M. A. Conway, \& P. E. Morris (Eds.), Theories of memory (pp. 189-209). Hove, U.K.: Erlbaum.

Gough, P. B., \& HiLlinger, M. L. (1980). Learning to read: An unnatural act. Bulletin of the Orton Society, 30, 179-196.

Hall, J. W., Wilson, K. P., Humphreys, M. S., Tinzmann, M. B., \& Bowyer, P. M. (1983). Phonemic-similarity effects in good vs. poor readers. Memory \& Cognition, 11, 520-527.

Hayes, D. S., \& SCHUlze, S. A. (1977). Visual encoding in preschoolers' serial retention. Child Development, $\mathbf{4 8}, 1066-1070$.

Henry, L. A. (1991). The effects of word length and phonemic similarity in young children's short-term memory. Quarterly Journal of Experimental Psychology, 43A, 35-52.

HiTCH, G. J., \& HALLIDAY, M. S. (1983). Working memory in children. Philosophical Transactions of the Royal Society of London: Series B, 302, 325-340.

Hitch, G. J., Halliday, M. S., Dodd, A., \& LitTler, J. E. (1989). Development of rehearsal in short-term memory: Differences between pictorial and spoken stimuli. British Journal of Developmental Psychology, 7, 347-362.

Hitch, G. J., HAllidAY, M. S., \& LitTLER, J. E. (1993). Development of memory span for spoken words: The role of rehearsal and item identification processes. British Journal of Developmental Psychology, 11, 159-169.

Hitch, G. J., Halliday, S., Schaafstal, A. M., \& Schraagen, J. M. C. (1988). Visual working memory in young children. Memory \& Cognition, 16, 120-132.

Hitch, G. J., WoOdIN, M. E., \& BAKer, S. (1989). Visual and phonological components of working memory in children. Memory \& Cognition, 17, 175-185.

Holligan, C., \& Johnston, R. S. (1988). The use of phonological information by good and poor readers in memory and reading tasks. Memory \& Cognition, 16, 522-532.

Hulme, C. (1984). Developmental differences in the effects of acoustic similarity on memory span. Developmental Psychology, 4, 650-652.

Hulme, C. (1987). The effects of acoustic similarity on memory in children: A comparison between visual and auditory presentation. Applied Cognitive Psychology, 1, 45-51.

Hulme, C., \& MACKENZIE, S. (1992). Working memory and severe learning difficulties. Hove, U.K.: Erlbaum.

Hulme, C., Thomson, N., Muir, C., \& Lawrence, A. (1984). Speech rate and the development of short-term memory span. Journal of Experimental Child Psychology, 47, 72-87.

Hulme, C., \& TORDOFF, V. (1989). Working memory development: The effects of speech rate, word length and acoustic similarity on serial recall. Journal of Experimental Child Psychology, 47, 72-87.

Johnston, R. S. (1982). Phonological coding in dyslexic readers. British Journal of Psychology, 73, 455-460.

JoHnSTON, R. S., \& ANDERSON, M. (1998). Memory span, naming speed and memory strategies in poor and normal readers. Memory, 6, 143-163.

JoHnston, R. S., \& ConNing, A. (1990). The effects of overt and covert rehearsal on the emergence of the phonological similarity effect in 5year-old children. British Journal of Developmental Psychology, 8 , 411-418.

Johnston, R. S., Johnson, C., \& Gray, C. (1987). The emergence of the word length effect in young children: The effects of overt and covert rehearsal. British Journal of Developmental Psychology, $\mathbf{5}_{2}$ 243-248.

JoHnston, R. S., RugG, M. D., \& ScotT, T. (1987). Phonological similarity effects, memory span and developmental reading disorders: The nature of the relationship. British Journal of Psychology, 78, 205-211.

JoRM, A. F. (1983). Specific reading retardation and working memory: A review. British Journal of Psychology, 74, 311-342.
Jorm, A. F., \& Share, D. L. (1983). Phonological recoding and reading acquisition. Applied Psycholinguistics, 4, 103-147.

KAIL, R. V. (1984). The development of memory in children (2nd ed.). New York: Freeman.

Mann, V. A., Liberman, I. Y., \& Shankweiler, D. (1980). Children's memory for sentences and word strings in relation to reading ability. Memory \& Cognition, 8, 329-335.

MAXWELL, A. E. (1959). A factor analysis of the Wechsler Intelligence Scale for Children. Journal of Educational Psychology, 29, 237-241.

McDougall, S., Hulme, C., Ellis, A., \& Monk, A. (1994). Learning to read: The role of short-term memory and phonological skills. Journal of Experimental Child Psychology, 58, 112-133.

MURRAY, D. J. (1968). Articulation and acoustic confusability in shortterm memory. Journal of Experimental Psychology, 78, 679-684.

Nelson, D. L., \& Brooks, D. H. (1973). Functional independence of pictures and verbal memory codes. Journal of Experimental Psychology, 98, 44-48.

NiCHOLSON, R. (1981). The relationship between memory span and processing speed. In M. Friedman, J. P. Das, \& N. Connor (Eds.), Intelligence and learning (pp. 179-184). New York: Plenum.

RACK, J. (1985). Orthographic and phonetic encoding in normal and dyslexic readers. British Journal of Psychology, 76, 325-340.

RUGEL, R. P. (1974). WISC subtest scores of disabled readers: A review with respect to Bannatyne's recategorization. Journal of Learning Disabilities, 7, 55 .

SAtTler, J. M. (1982). Assessment of children's intelligence and special abilities. Boston: Allyn \& Bacon.

Seymour, P. H. K., \& Porpodas, C. (1980). Lexical and non-lexical processing of spelling in dyslexia. In U. Frith (Ed.), Cognitive processes in spelling. London: Academic Press.

Shankweiler, D., Liberman, I. Y., Mark, I., Fowler, C., \& Fischer, F. (1979). The speech code and learning to read. Journal of Experimental Psychology: Human Learning \& Memory, 5, 531-545.

SNOWLING, M. J. (1980). The development of grapheme-phoneme correspondences in normal and dyslexic readers. Journal of Experimental Child Psychology, 29, 294-305.

SWANSON, H. L. (1984). Semantic and verbal memory codes in learningdisabled readers. Journal of Experimental Child Psychology, 37, 124140.

SWANSON, H. L. (1987). Verbal coding deficits in learning-disabled readers: Remembering pictures and words. In H. L. Swanson (Ed.), Memory and learning disabilities (Advances in Learning and Behavioral Disabilities, Suppl. 2, pp. 123-304). Greenwich, CT: JAI Press.

Torgesen, J. K. (1978). Memorization processes in reading-disabled children. Journal of Educational Psychology, 69, 471-478.

Torgesen, J. K., \& Goldman, T. (1977). Verbal rehearsal and shortterm memory in reading-disabled children. Child Development, $\mathbf{4 8}$, 56-60.

Vellutino, F. R. (1977). Alternative conceptualization of dyslexia: Evidence in support of a verbal deficit hypothesis. Harvard Educational Review, 47, 334-354.

Vellutino, F. R. (1979). Dyslexia: Theory and research. Cambridge, MA: MIT Press.

Vellutino, F. R., Pruzek, R., Steger, J. A., \& Meshoulam, U. (1973). Immediate visual recall in poor readers as a function of orthographic-linguistic familiarity. Cortex, 9, 368-384.

Vellutino, F. R., \& Scanlon, D. M. (1987). Linguistic coding and reading ability. In S. Rosenberg (Ed.), Advances in applied psycholinguistics (pp. 1-69). New York: Cambridge University Press.

WECHSLER, D. (1974). Wechsler Intelligence Scale for ChildrenRevised. New York: Psychological Corp.

(Manuscript received February 20, 2001; revision accepted for publication November 13, 2003.) 